\title{
A Multi-Criteria Decision Making to Support Major Selection of Senior High School
}

\author{
Adhistya Erna Permanasari ${ }^{1}$, Marsetyo Wisaksono ${ }^{2}$, Sri Suning Kusumawardani ${ }^{3}$
}

\begin{abstract}
Senior high school students need to select a specialization, such as Mathematics and Natural Sciences, Social Sciences, or Language and Culture. This selection process can be improved by using Multi-Criteria Decision Making (MCDM) methods. When MCDM methods are implemented, AHP method has an accuracy of $61 \%$. In contrast, AHP-Fuzzy TOPSIS 1 and AHP-Fuzzy TOPSIS 2 have an accuracy of $75 \%$. This research implements tests and analyzes the new MCDM method, which is the Hybrid MCDM Model, in helping the aforementioned specialization selection process. There are four basic steps in Hybrid MCDM Model: performing experimental design to obtain attributes' weight and criteria, evaluating MCDM with the three existing methods, performing RSM regression to derive mathematical model and decision making. This research introduces data normalization to the mathematical model which results in better implementation of Hybrid MCDM Model in the senior high school students' specialization selection process. Hybrid MCDM Model in the senior high school student specialization selection has an accuracy of $86 \%$, which includes $11 \%$ accuracy improvements compared to other applied MCDM methods.
\end{abstract}

Keywords-Major Selection, Hybrid MCDM, Experimental Design, Senior High School.

\section{INTRODUCTION}

Senior High School is formal secondary education. At the senior high school level, students can choose a specific major according to their interests, talents, and abilities. In Indonesia, a major system level has been applied since the Colonial era. There are three major selection, Natural Sciences, Social Sciences, and Language. Generally, most schools divide the major into Natural Sciences and Social Sciences. This specialization is useful so that students who have the same talents, interests, skills, and similar abilities can be grouped into the same group. A major study is also introduced to encourage students more focused based on their interests and academic ability. Therefore, an appropriate major will increase student interest in their learning environment. It is expected that the teaching and learning activities in the classroom can run smoothly with no difficulties since students have the same basic capability. There is a need to choose an appropriate major for students. Lack of interest due to errors in the selection of a specialization can cause students to lose their enthusiasm in learning, causing decreased academic achievement [1].

1,2,3 Department of Electrical and Information Engineering, Faculty of Engineering, Universitas Gadjah Mada, Jln. Grafika No. 2, Kampus UGM, Yogyakarta, INDONESIA, 55281 (Tel. +62-274552305; email: adhistya@ugm.ac.id)
Currently, most of the major selection in senior high school is still made manually. The manual method for a majoring student based on student's interest and grade, the teacher will write down the major of the student on the report book. This way certainly has some drawbacks to them related to the process objectivity and the time efficiency. The growth of computer technology has led to the support of some aspects of the education field.

The process of major selection can be helped by Multiple Criteria Decision Making (MCDM) method. MCDM is a decision-making method for determining the best alternative of some available alternatives based on specific criteria [2]. Criteria are usually the size or rule or standard used in decisionmaking. Many approaches have been developed to solve the problem in educational [3]-[8].

One of the MCDM methods that can be implemented is the novel of the MCDM model [9]. The model is an MCDM technique that incorporates three commonly used MCDM techniques. These models, Simple Additive Weighting (SAW), Technique for Order of Preference by Similarity to Ideal Solution (TOPSIS), and Gray Relational Analysis (GRA). It combines these three MCDM methods and takes advantage of each method.

This research aims to develop a model classify senior high school students' major selection. The model can be used to aid human cognition by integrating various resources of information and providing relevant knowledge. Finally, it can optimize the process of decision-making. This research will explain the implementation of MCDM model [9] in decision making specialization for high school students, analyze the result, and compare the results to another MCDM model. The remainder of the paper is structured as follows. Section II illustrates methods, Section III reports the model development, while Section IV describes results analysis. Finally, Section V presents the conclusion.

\section{METHODS}

In previous research, a novel MCDM approach was proposed [9]. There are three advantages of the Hybrid MCDM model. Fig. 1 shows the experimental flow diagram.

First, conduct an experimental design to weight the criteria. It is done to avoid subjectivity and sensitivity results so that Hybrid MCDM Model's output is more reasonable and reliable. The second advantage is that there is a regression model that helps decision-makers. Therefore, decision makers can choose and analyze the factors and criteria quickly. Also, if there are new alternatives or omitted alternatives, the decision makers simply use this regression model and get the final result. The third advantage, this method combines several methods (SAW, 


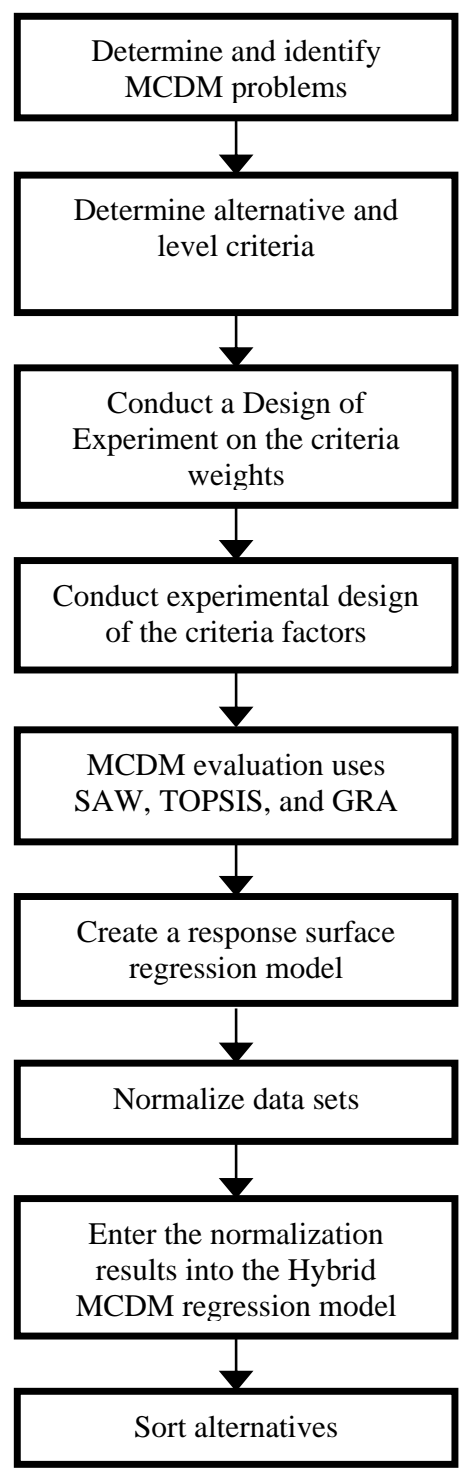

Fig. 1 Experimental flow diagram.

TOPSIS, GRA) that utilize the best feature of each method. With this merger, the results are more reliable and reasoned.

The method consists of four basic phases. In the first stage, we identify alternate-related issues along with the criteria and perform the experimental design or Design of Experiment (DoE) procedure. The DoE procedure at this stage is the orthogonal array for the design of the criteria factor and the optimal Latin hypercube design for the design of the weighting criteria. The results of this first phase are used for MCDM evaluation.

In the second stage, the previous stage results are used for calculations using MCDM SAW, TOPSIS, and GRA methods. Using orthogonal arrays that have been obtained in the preceding stage and the given criteria weight, the calculations are done using SAW, TOPSIS, and GRA. Further, the average value of the three methods is calculated and used to create a regression model.

In the third stage, the approximate response surface model is made using a second-degree polynomial function. This model is based on the weight of the criteria generated in the first stage and the average rating in response. This stage produces the mathematical model used in the next step.

Finally, in the fourth stage, we incorporated the values of the normalized criteria into the mathematical model obtained in the previous stage. The alternative with the highest rating is the best.

\section{MOdel DeVElopment}

The research material used in this study uses secondary data obtained from existing sources. We collected secondary data from previous research [1]. These data are the data used to determine the major selection in SMA X, Indonesia, in the academic year 2015/2016. Student data contains these following items.

- Academic reports of Junior-Senior high school grades from semester 1 to semester 5 .

- National exam scores (UN).

- Student test scores.

- Data of student majors.

- Student placement test.

- Major selection result of class X student.

After the data collection is complete, then it is followed by model development. As described before the Hybrid MCDM Model is divided into four stages.

1) Conducting Experimental Design to Get a Design of Criteria Factor and Weight Criteria: It is the first stage where we identified MCDM issues. The main MCDM problem in this research is a major selection determinant of senior high school students. There are 92 students or alternatives to be determined into one of two major, namely Natural Science and Social Sciences. Also, there are six aspects or criteria used, namely the average score of the report, major study, the average value of the school exam, the average value of placement, and the average value of the national exam.

Furthermore, alternatives and criteria levels are determined. On this issue, there are 92 alternatives available and should be specified in one of the major. Aspects or criteria used are six criteria, consisting of five criteria containing quantitative data and one criterion providing qualitative data, including major study. Thus, this criterion should be converted into quantitative data, where Social Science is changed to 1 , and Natural Science is changed to 2 . All criteria will be selected for these maximum values. Referring to the initial data; the criterion level used is as follows.

1. The average score of the academic report: the minimum score is 59.22 , and the maximum value is 88.58 .

2. Student major: the minimum value is 1 , and the maximum value is 2 .

3. The average value of a school exam: the minimum score is 38 , and the maximum value is 100 .

4. The average score of placement test: minimum value is 15.5 , and the maximum value is 90.5 . 
TABLE I

ATtRIBute Weights FOR SENIOR High SCHOOL STUdENT MAJOR SELECTION

\begin{tabular}{|c|c|c|c|c|c|}
\hline $\begin{array}{c}\text { Weight } \\
\text { no. }\end{array}$ & $\begin{array}{c}\text { Average } \\
\text { of } \\
\text { academic } \\
\text { report } \\
\text { score }\end{array}$ & $\begin{array}{c}\text { Student } \\
\text { major }\end{array}$ & $\begin{array}{c}\text { Average } \\
\text { value of a } \\
\text { school } \\
\text { exam }\end{array}$ & $\begin{array}{c}\text { Average } \\
\text { score of } \\
\text { placement } \\
\text { test }\end{array}$ & $\begin{array}{c}\text { Average } \\
\text { score of } \\
\text { the } \\
\text { national } \\
\text { exam }\end{array}$ \\
\hline W1 & 7 & 9 & 5 & 3 & 8 \\
\hline W2 & 5 & 8 & 3 & 7 & 9 \\
\hline W3 & 8 & 7 & 3 & 5 & 9 \\
\hline W4 & 8 & 9 & 3 & 5 & 7 \\
\hline W5 & 7 & 8 & 3 & 5 & 9 \\
\hline W6 & 5 & 7 & 3 & 8 & 9 \\
\hline
\end{tabular}

TABLE II

ORTHOGONAL ARRAY OF SENIOR HIGH SCHOOL STUDENT MAJOR SELECTION

\begin{tabular}{|c|c|c|c|c|c|}
\hline $\begin{array}{c}\text { Alterna- } \\
\text { tive }\end{array}$ & $\begin{array}{c}\text { Average } \\
\text { of } \\
\text { academic } \\
\text { report } \\
\text { score }\end{array}$ & $\begin{array}{c}\text { Student } \\
\text { Major }\end{array}$ & $\begin{array}{c}\text { Average } \\
\text { value of } \\
\text { a school } \\
\text { exam }\end{array}$ & $\begin{array}{c}\text { Average } \\
\text { score of } \\
\text { placement } \\
\text { test }\end{array}$ & $\begin{array}{c}\text { Average } \\
\text { score of } \\
\text { the } \\
\text { national } \\
\text { exam }\end{array}$ \\
\hline A1 & 59.22 & 1 & 38 & 15.5 & 35 \\
\hline A2 & 59.22 & 1 & 38 & 90.5 & 93.75 \\
\hline A3 & 59.22 & 1 & 100 & 15.5 & 93.75 \\
\hline A4 & 59.22 & 1 & 100 & 90.5 & 35 \\
\hline A5 & 59.22 & 2 & 38 & 15.5 & 93.75 \\
\hline A6 & 59.22 & 2 & 38 & 90.5 & 35 \\
\hline A7 & 59.22 & 2 & 100 & 15.5 & 35 \\
\hline A8 & 59.22 & 2 & 100 & 90.5 & 93.75 \\
\hline A9 & 88.58 & 1 & 38 & 15.5 & 93.75 \\
\hline A10 & 88.58 & 1 & 38 & 90.5 & 35 \\
\hline A11 & 88.58 & 1 & 100 & 15.5 & 35 \\
\hline A12 & 88.58 & 1 & 100 & 90.5 & 93.75 \\
\hline A13 & 88.58 & 2 & 38 & 15.5 & 35 \\
\hline A14 & 88.58 & 2 & 38 & 90.5 & 93.75 \\
\hline A15 & 88.58 & 2 & 100 & 15.5 & 93.75 \\
\hline A16 & 88.58 & 2 & 100 & 90.5 & 35 \\
\hline
\end{tabular}

5. The average score of the national exam: the minimum score is 35 , and the maximum value is 93.75 .

Once the alternatives and criteria levels are determined, then we do a Design of Experiment (DoE) or experimental design on the criteria weight. Saaty's 9-point scale is used on the criteria weight. The DoE technique approach at this stage is the optimal Latin hypercube design. In the optimal Latin hypercube design, the number of designs should be higher than the number of factors. The number of designs in this study is $n+1$, where $\mathrm{n}$ is the number of criteria factors. So with the criterion factor of 5 , the number of criteria weight used is 6 . The weight of criteria used consists of the weight W1 to the weight of W6. The weights are listed in Table I.

The next step is the experimental design on the criterion factor with two-level orthogonal array $L_{16}\left(2^{5}\right)$. The orthogonal array table is shown in Table II.

On the orthogonal array $L_{16}\left(2^{5}\right)$, there are 16 experimental designs that run with two levels for each factor and five orthogonal array columns. The orthogonal array has two levels.
TABLE III

NORMALIZATION RESULTS OF ORTHOGONAL ARRAY

\begin{tabular}{|c|c|c|c|c|c|}
\hline $\begin{array}{c}\text { Alternati } \\
\text { ve }\end{array}$ & $\begin{array}{c}\text { The } \\
\text { average } \\
\text { score of } \\
\text { academic } \\
\text { report }\end{array}$ & $\begin{array}{c}\text { Student } \\
\text { Major }\end{array}$ & $\begin{array}{c}\text { The } \\
\text { average } \\
\text { value of } \\
\text { a school } \\
\text { exam }\end{array}$ & $\begin{array}{c}\text { The } \\
\text { average } \\
\text { score of } \\
\text { placement } \\
\text { test }\end{array}$ & $\begin{array}{c}\text { The } \\
\text { average } \\
\text { score of } \\
\text { the } \\
\text { national } \\
\text { exam }\end{array}$ \\
\hline A1 & 0.19650 & 0.15811 & 0.12559 & 0.05968 & 0.12366 \\
\hline A2 & 0.19650 & 0.15811 & 0.12559 & 0.34848 & 0.33122 \\
\hline A3 & 0.19650 & 0.15811 & 0.33050 & 0.05968 & 0.33122 \\
\hline A4 & 0.19650 & 0.15811 & 0.33050 & 0.34848 & 0.12366 \\
\hline A5 & 0.19650 & 0.31623 & 0.12559 & 0.05968 & 0.33122 \\
\hline A6 & 0.19650 & 0.31623 & 0.12559 & 0.34848 & 0.12366 \\
\hline A7 & 0.19650 & 0.31623 & 0.33050 & 0.05968 & 0.12366 \\
\hline A8 & 0.19650 & 0.31623 & 0.33050 & 0.34848 & 0.33122 \\
\hline A9 & 0.29392 & 0.15811 & 0.12559 & 0.05968 & 0.33122 \\
\hline A10 & 0.29392 & 0.15811 & 0.12559 & 0.34848 & 0.12366 \\
\hline A11 & 0.29392 & 0.15811 & 0.33050 & 0.05968 & 0.12366 \\
\hline A12 & 0.29392 & 0.15811 & 0.33050 & 0.34848 & 0.33122 \\
\hline A13 & 0.29392 & 0.31623 & 0.12559 & 0.05968 & 0.12366 \\
\hline A14 & 0.29392 & 0.31623 & 0.12559 & 0.34848 & 0.33122 \\
\hline A15 & 0.29392 & 0.31623 & 0.33050 & 0.05968 & 0.33122 \\
\hline A16 & 0.29392 & 0.31623 & 0.33050 & 0.34848 & 0.12366 \\
\hline & & & & & \\
\hline
\end{tabular}

TABLE IV

RESUlTS OF AVERAGE RANK FOR EACH CRITERIA WEIGHT

\begin{tabular}{|c|c|c|c|c|c|c|}
\hline $\begin{array}{c}\text { Alterna- } \\
\text { tives }\end{array}$ & $\mathbf{W 1}$ & $\mathbf{W 2}$ & $\mathbf{W 3}$ & $\mathbf{W 4}$ & $\mathbf{W 5}$ & $\mathbf{W 6}$ \\
\hline A1 & 0.3304 & 0.3099 & 0.3238 & 0.3266 & 0.3219 & 0.3063 \\
\hline A2 & 0.5809 & 0.6520 & 0.6365 & 0.6014 & 0.6307 & 0.6700 \\
\hline A3 & 0.5949 & 0.5413 & 0.5728 & 0.5359 & 0.5686 & 0.5320 \\
\hline A4 & 0.5163 & 0.5534 & 0.5251 & 0.5326 & 0.5215 & 0.5722 \\
\hline A5 & 0.6347 & 0.5858 & 0.6093 & 0.6039 & 0.6181 & 0.5637 \\
\hline A6 & 0.5577 & 0.5978 & 0.5624 & 0.6006 & 0.5719 & 0.6037 \\
\hline A7 & 0.5718 & 0.4859 & 0.4955 & 0.5350 & 0.5080 & 0.4639 \\
\hline A8 & 0.7633 & 0.7880 & 0.7495 & 0.7470 & 0.7620 & 0.7897 \\
\hline A9 & 0.5723 & 0.5366 & 0.5865 & 0.5503 & 0.5755 & 0.5275 \\
\hline A10 & 0.4889 & 0.5488 & 0.5393 & 0.5470 & 0.5287 & 0.5678 \\
\hline A11 & 0.5058 & 0.4171 & 0.4656 & 0.4714 & 0.4532 & 0.4111 \\
\hline A12 & 0.6794 & 0.7054 & 0.7146 & 0.6759 & 0.6987 & 0.7248 \\
\hline A13 & 0.5487 & 0.4803 & 0.5107 & 0.5495 & 0.5154 & 0.4580 \\
\hline A14 & 0.7263 & 0.7755 & 0.7719 & 0.7699 & 0.7727 & 0.7775 \\
\hline A15 & 0.7459 & 0.6350 & 0.6825 & 0.6782 & 0.6840 & 0.6120 \\
\hline A16 & 0.6548 & 0.6474 & 0.6335 & 0.6749 & 0.6357 & 0.6526 \\
\hline
\end{tabular}

Namely low level and high level. Low levels and high levels are replaced with minimum values and maximum values that are present at the criteria level.

A further step is normalized data of Table II by using (1).

$$
r_{i j}=\frac{x_{i j}}{\sqrt{\sum_{k=1}^{m} x_{k j}^{2}}} ; \quad i=1, \ldots, m ; j=1, \ldots
$$

where $r_{i j}$ is decision matrix normalization from alternative $i$ and criteria $j$, while $x_{i j}$ is an element of the alternative matrix $i$ to criteria $j$. The results of the normalization are presented in Table III.

2) Evaluate MCDM using Three Existing Method: At this stage, calculations are made using SAW, TOPSIS, and GRA 
TABLE V

RESUltS OF POLYNOMIAL REGRESSION CALCULATION

\begin{tabular}{|c|c|c|c|}
\hline Term & Coefficient & Term & Coefficient \\
\hline $\boldsymbol{T}_{\mathbf{0}}=\mathbf{1}$ & $\begin{array}{c}a_{0}= \\
-0.1535\end{array}$ & $\boldsymbol{T}_{\mathbf{1 1}}=\boldsymbol{x}_{\mathbf{1}} * \boldsymbol{x}_{\mathbf{2}}$ & $\begin{array}{c}a_{11}= \\
-0.01074\end{array}$ \\
\hline $\boldsymbol{T}_{\mathbf{1}}=\boldsymbol{x}_{\mathbf{1}}$ & $\begin{array}{c}a_{1}= \\
0.1484\end{array}$ & $\boldsymbol{T}_{\mathbf{1 2}}=\boldsymbol{x}_{\mathbf{1}} * \boldsymbol{x}_{\mathbf{3}}$ & $\begin{array}{c}a_{12}= \\
-0.03925\end{array}$ \\
\hline $\boldsymbol{T}_{\mathbf{2}}=\boldsymbol{x}_{\mathbf{2}}$ & $\begin{array}{c}a_{2}= \\
0.0706\end{array}$ & $\boldsymbol{T}_{\mathbf{1 3}}=\boldsymbol{x}_{\mathbf{1}} * \boldsymbol{x}_{\mathbf{4}}$ & $\begin{array}{c}a_{13}= \\
-0.01510\end{array}$ \\
\hline $\boldsymbol{T}_{\mathbf{3}}=\boldsymbol{x}_{\mathbf{3}}$ & $\begin{array}{c}a_{3}= \\
0.1764\end{array}$ & $\boldsymbol{T}_{\mathbf{1 4}}=\boldsymbol{x}_{\mathbf{1}} * \boldsymbol{x}_{\mathbf{5}}$ & $\begin{array}{c}a_{14}= \\
-0.00575\end{array}$ \\
\hline $\boldsymbol{T}_{\mathbf{4}}=\boldsymbol{x}_{\mathbf{4}}$ & $\begin{array}{c}a_{4}= \\
0.1486\end{array}$ & $\boldsymbol{T}_{\mathbf{1 5}}=\boldsymbol{x}_{\mathbf{2}} * \boldsymbol{x}_{\mathbf{3}}$ & $\begin{array}{c}a_{15}= \\
-0.01395\end{array}$ \\
\hline $\boldsymbol{T}_{\mathbf{5}}=\boldsymbol{x}_{\mathbf{5}}$ & $\begin{array}{c}a_{5}= \\
0.1306\end{array}$ & $\boldsymbol{T}_{\mathbf{1 6}}=\boldsymbol{x}_{\mathbf{2}} * \boldsymbol{x}_{\mathbf{4}}$ & $\begin{array}{c}a_{16}= \\
-0.00655\end{array}$ \\
\hline $\boldsymbol{T}_{\mathbf{6}}=\boldsymbol{x}_{\mathbf{1}} * \boldsymbol{x}_{\mathbf{1}}$ & $\begin{array}{c}a_{6}= \\
-0.00068\end{array}$ & $\boldsymbol{T}_{\mathbf{1 7}}=\boldsymbol{x}_{\mathbf{2}} * \boldsymbol{x}_{\mathbf{5}}$ & $\begin{array}{c}a_{17}= \\
-0.00453\end{array}$ \\
\hline $\boldsymbol{T}_{\mathbf{7}}=\boldsymbol{x}_{\mathbf{2}} * \boldsymbol{x}_{\mathbf{2}}$ & $\begin{array}{c}a_{7}= \\
0.01295\end{array}$ & $\boldsymbol{T}_{\mathbf{1 8}}=\boldsymbol{x}_{\mathbf{3}} * \boldsymbol{x}_{\mathbf{4}}$ & $\begin{array}{c}a_{18}= \\
-0.01811\end{array}$ \\
\hline $\boldsymbol{T}_{\mathbf{8}}=\boldsymbol{x}_{\mathbf{3}} * \boldsymbol{x}_{\mathbf{3}}$ & $\begin{array}{c}a_{8}= \\
0.01043\end{array}$ & $\boldsymbol{T}_{\mathbf{1 9}}=\boldsymbol{x}_{\mathbf{3}} * \boldsymbol{x}_{\mathbf{5}}$ & $\begin{array}{c}a_{19}= \\
-0.00988\end{array}$ \\
\hline $\boldsymbol{T}_{\mathbf{9}}=\boldsymbol{x}_{\mathbf{4}} * \boldsymbol{x}_{\mathbf{4}}$ & $\begin{array}{c}a_{9}= \\
-0.00544\end{array}$ & $\boldsymbol{T}_{\mathbf{2 0}}=\boldsymbol{x}_{\mathbf{4}} * \boldsymbol{x}_{\mathbf{5}}$ & $\begin{array}{c}a_{20}= \\
-0.00471\end{array}$ \\
\hline $\boldsymbol{T}_{\mathbf{1 0}}=\boldsymbol{x}_{\mathbf{5}} * \boldsymbol{x}_{\mathbf{5}}$ & $\begin{array}{c}a_{10}= \\
-0.00471\end{array}$ & $\begin{array}{l}\mathbf{S}=\mathbf{0 . 0 1 0 3 4 0 8} \mathbf{R}-\mathbf{S q}= \\
\mathbf{9 9 . 3 6 \%}, \mathbf{R}-\mathbf{S q}(\mathbf{a d j})=\mathbf{9 9 . 1 9 \%}\end{array}$ \\
\hline
\end{tabular}

methods. The data are orthogonal arrays of senior high school students' major selection in Table II, and the weight of the criteria for senior high school students in Table I. Each weighting criterion $\mathrm{W} 1$ to $\mathrm{W} 6$ is calculated using all three methods. In the SAW method, the results should be normalized before the average of three methods is calculated. The calculation result of each method is then calculated using (2).

$$
C_{A V E}=\frac{C_{S A W}+C_{T O P S I S}+C_{G R A}}{3}
$$

where $C_{A V E}$ is the value of average rank, $C_{S A W}, C_{T O P S I S}$, dan $C_{G R A}$ are the rank value of SAW, the TOPSIS, and GRA, respectively. The result of the average rating on each criterion weight is given in Table IV.

3) Develop a Mathematical Model Based Response Surface Method (RSM) Regression: RSM utilizes polynomial regression to model the relationship between several criteria with average grade values. The data used are weighted normalized orthogonal arrays and the result of the average rating scores on each of the criteria weights contained in Table IV. Weighted orthogonal arrays are data from Table III multiplied by the weight of the Table I criteria. Furthermore, they are incorporated into the Minitab software for polynomial regression. The results of polynomial regression calculations that used to form a mathematical model are found in Table V.

The calculation has a significant coefficient of determination with a value $99.36 \%$. Thus, the relationship between the rating value and some criteria can be explained well by the mathematical model. Next, the results in Table $\mathrm{V}$ are made
TABLE VI

SAMPLING RESULTS OF STUdENT MAJOR SELECTION BASED HybRID MCDM MODEL

\begin{tabular}{|c|l|c|}
\hline No. & Name & Major selections \\
\hline 1 & Student 1 & Natural Science \\
\hline 2 & Student 2 & Social Science \\
\hline 3 & Student 3 & Social Science \\
\hline 4 & Student 4 & Natural Science \\
\hline 5 & Student 5 & Social Science \\
\hline 6 & Student 6 & Social Science \\
\hline 7 & Student 7 & Natural Science \\
\hline 8 & Student 8 & Natural Science \\
\hline 9 & Student 9 & Social Science \\
\hline 10 & Student 10 & Social Science \\
\hline
\end{tabular}

according to the general equations of the mathematical model (3).

$$
y=a_{0} T_{0}+a_{1} T_{1}+\cdots+a_{n} T_{n}
$$

where $y$ is a final value, $a_{n}$ is the $n$-th coefficient, and $T_{n}$ is term to- $n$.

4) Make a Decision: At this stage, the initial data set is first normalized using (4).

$$
r_{i j}=w x_{j}^{-}+\frac{w x_{j}^{+}-w x_{j}^{-}}{x_{j}^{+}-x_{j}^{-}}\left(x_{i j}-x_{j}^{-}\right)
$$

where $r_{i j}$ is normalization results, $x_{i j}$ is initial data set, and $w x_{i j}$ is weighted normalization orthogonal array, $x_{j}^{+}=$ $\max \left\{x_{i j}, i=1, \ldots, m\right\} \quad$ dan $\quad x_{j}^{-}=\min \left\{x_{i j}, i=1, \ldots, m\right\}$, $w x_{j}^{+}=\max \left\{w x_{i j}, i=1, \ldots, m *(n+1)\right\} \quad$ and $\quad w x_{j}^{-}=$ $\min \left\{w x_{i j}, i=1, \ldots, m *(n+1)\right\}$.

Furthermore, the normalized results data are incorporated into the MCDM Hybrid regression model. The general form of the MCDM Hybrid regression model is found in (3) with the variables used in Table IV. The MCDM Hybrid regression model used is found in (5).

$$
\begin{array}{r}
y=(-0,1535)(1)+(0,1484)\left(x_{1}\right)+\cdots \\
+(-0,00471)\left(x_{4} * x_{5}\right)
\end{array}
$$

with $y$ is the final value, then $x_{n}$ is the result of normalization obtained in the previous step and multiplied by the weight of the criterion. At this stage, the importance of all criteria is considered equal. Therefore the weight of the criterion is considered 1. For that, the $x_{n}$ the variable is the result of normalization from the previous stage. For example, variable $x_{1}$ is the normalization result of the average academic report. The normalized results already incorporated into the MCDM hybrid regression model yield the values used to sort the alternatives.

Furthermore, the average value is calculated from the overall final value. If the student's score is higher than the average score, go to Natural Science. While, if the student's score is less than the average score, Social Science is the student major. The sampling result of this major selection is shown in Table VI 
TABLE VII

COMPARATIVE RESUlTS OF DETERMINATION SENIOR HigH SCHOOL MAJOR SELECTION

\begin{tabular}{|c|c|c|c|c|}
\hline Method & $\begin{array}{c}\text { Hybrid } \\
\text { MCDM } \\
\text { Model }\end{array}$ & AHP & $\begin{array}{c}\text { AHP- } \\
\text { Fuzzy } \\
\text { TOPSIS 1 }\end{array}$ & $\begin{array}{c}\text { AHP- } \\
\text { Fuzzy } \\
\text { TOPSIS 2 }\end{array}$ \\
\hline $\begin{array}{c}\text { Number of } \\
\text { suitability }\end{array}$ & 79 data & $\begin{array}{c}56 \\
\text { data }\end{array}$ & 69 data & 69 data \\
\hline $\begin{array}{c}\text { Accuracy } \\
\text { percentage }\end{array}$ & $86 \%$ & $61 \%$ & $75 \%$ & $75 \%$ \\
\hline
\end{tabular}

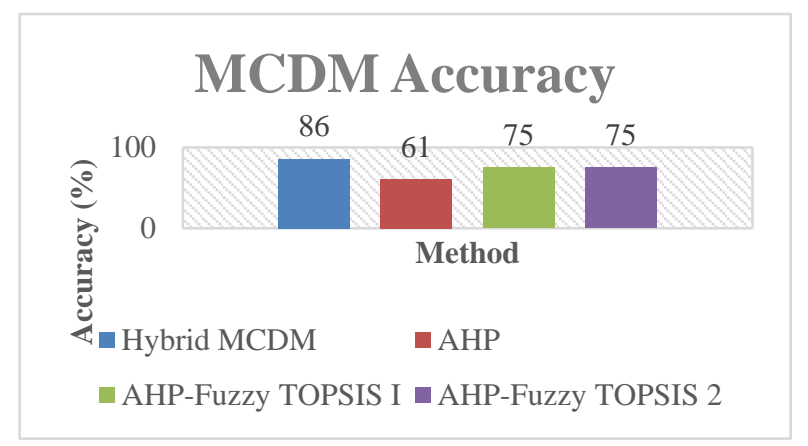

Fig. 2 A Comparative chart results of the MCDM method.

where the major selections column shows the major of each student based on the hybrid MCDM approach.

\section{Results ANALYSIS}

\section{A. Accuracy Test}

This section analyzes the major selection results of senior high school students. They have done with the hybrid MCDM Model by performing an accuracy test. The purpose of using the accuracy test is to know the level of closeness between senior high school students' outcomes from hybrid MCDM Model method and the manual result from school. In this accuracy test, the data used is the exact number of measurements and the amount of data available. The exact number of measurements is the amount of senior high school students' data using the hybrid MCDM Model. It equals the result of senior high school student's education manually. The exact number of measurement data will be divided by the amount of existing data and multiplied $100 \%$. The accuracy test is performed with (6).

$$
\text { Accuracy }(\%)=\frac{\sum \text { accepted value }}{\sum \text { observed value }} \times 100 \%
$$

After the experiment, hybrid MCDM Model method calculations have 79 accepted value out of 92 students. The accuracy test of the results is found in (7).

$$
\text { Accuracy }(\%)=\frac{79}{92} \times 100 \%=86 \%
$$

\section{B. Comparing with Other MCDM Model}

After conducting the process of a hybrid model, the results of the model are being compared with the results of other MCDM methods with the same data set (AHP, AHP-Fuzzy TOPSIS 1, and AHP-Fuzzy TOPSIS 2). The result is the AHP method has suitability of 56 data with the accuracy is $61 \%$, the
AHP-Fuzzy TOPSIS 1 has suitability of 69 data, and the accuracy is 75\%, and AHP-Fuzzy method TOPSIS 2 has suitability of 69 data and the percentage of accuracy value is 75\%. Table VII and Fig. 2 display the comparative results.

From Table VII and Fig. 2, the hybrid method MCDM Model outperforms accuracy than other methods. The accuracy value of the MCDM Hybrid method is $25 \%$ higher than the AHP method and $11 \%$ higher than the AHP-Fuzzy TOPSIS 1 and the AHP-Fuzzy TOPSIS 2 method. Thus, the results of the hybrid MCDM Model Experienced an $11 \%$ increase in accuracy value from other MCDM methods used in the study with the same data set. The result of this comparison can be considered in the selection of MCDM methods both in the process of senior high school major selection and in other cases.

\section{CONCLUSIONS}

In this study, we present the implementation of the computer algorithm to support decision-makers in the educational field. MCDM approach has been used to determine major selection in senior high school. Based on the results, it is concluded that the initial data normalization can be incorporated into the MCDM hybrid regression model. It generates values to sort the alternatives. This shows the method of Hybrid MCDM Model can already be implemented in the process. The process of high school students with the Hybrid MCDM Model has an accuracy of $86 \%$. There is an increase in the accuracy value of $11 \%$ from other MCDM methods.

\section{REFERENCES}

[1] F.N. Khasanah, A.E. Permanasari, and S.S. Kusumawardani, "Fuzzy MADM for major selection at senior high school," ICITACEE 2015 - 2nd International Conference on Information Technology, Computer, and Electrical Engineering: Green Technology Strengthening in Information Technology, Electrical and Computer Engineering Implementation, Proceedings, 2016, pp. 41-45.

[2] E. Triantaphyllou, "Introduction to Multi-Criteria Decision Making," Multi-criteria Decision Making Methods: A Comparative Study, Boston, USA: Springer US, 2000.

[3] H.-Y. Wu, H.-S. Wu, I.-S. Chen, and H.-C. Chen, "Exploring the critical influential factors of creativity for college students: A multiple criteria decision-making approach," Think. Ski. Creat., Vol. 11, pp. 1-21, Mar. 2014.

[4] S.A.H. Syed Hassan, S.C. Tan, and K.M. Yusof, "MCDM for Engineering Education: Literature Review and Research Issues," Engineering Education for a Smart Society: World Engineering Education Forum \{\&\} Global Engineering Deans Council 2016, M. E. Auer and K.-S. Kim, Eds. Cham, Switzerland: Springer International Publishing, 2018, pp. 204-214.

[5] Y.D.L. Widyasari, A.E. Permanasari, R. Ferdiana, and L.E. Nugroho, "Analysis of data quality maturity in a higher education institution," Adv. Sci. Lett., Vol. 21, No. 10, pp. 3059-3063, 2015.

[6] W. Ho, P.K. Dey, and H.E. Higson, “Multiple Criteria Decision Making Techniques in Higher Education,” Int. J. Educ. Manag., Vol. 20, No. 5, pp. 319-337, 2006.

[7] Y.-H. Chiang, "MCDM Modelling on Learning Achievement Determinants of Undergraduate Students in Taiwan," Int. J. Educ. Dev., vol. 6, pp. 130-141, 2015.

[8] T.E. Erkan and B.D. Rouyendegh, "Curriculum Change Parameters Determined by Multi Criteria Decision Making (MCDM)," Procedia Soc. Behav. Sci., Vol. 116, pp. 1744-1747, Feb. 2014.

[9] P. Wang, Z. Zhu, and Y. Wang, "A Novel Hybrid MCDM Model Combining the SAW, TOPSIS and GRA Methods Based on Experimental Design," Inf. Sci. (Ny)., Vol. 345, pp. 27-45, 2016. 